\title{
Peripheral neuropathy in survivors of childhood acute lymphoblastic leukemia
}

\author{
Sindhu Ramchandren ${ }^{1}$, Marcia Leonard ${ }^{2}$, Rajen J. Mody², Janet E. Donohue ${ }^{2}$, Judith \\ Moyer $^{2}$, Raymond Hutchinson ${ }^{2}$, and James G. Gurney ${ }^{2}$ \\ ${ }^{1}$ Department of Neurology, Detroit Medical Center, Wayne State University, Detroit, MI \\ ${ }^{2}$ Comprehensive Cancer Center and Department of Pediatrics, University of Michigan, Ann Arbor, \\ MI, USA
}

\section{Abstract}

Acute lymphoblastic leukemia (ALL) is the most common form of cancer in children. Recent advances in treatment have led to dramatically improved survival rates. Standard ALL treatment includes multiple administrations of the chemotherapeutic drug vincristine, which is a known neurotoxic agent. Although peripheral neuropathy is a well-known toxicity among children receiving vincristine acutely, the long-term effects on the peripheral nervous system in these children are not clear. The objective of this study was to determine the prevalence of neuropathy and its impact on motor function and quality of life (QOL) among children who survived ALL. Thirty-seven survivors of childhood ALL aged 8-18 underwent evaluation for neuropathy through self-reported symptoms, standardized examinations, and nerve conduction studies (NCS). Functional impact of neuropathy was assessed using the Bruininks-Oseretsky test of Motor Proficiency (BOT-2). QOL was assessed using the PedsQL. Nerve conduction study abnormalities were seen in $29.7 \%$ of children who were longer than 2 years off therapy for ALL. Most children with an abnormal examination or NCS did not have subjective symptoms. Although overall motor function was below population norms on the BOT-2, presence of neuropathy did not significantly correlate with motor functional status or QOL.

\section{Keywords}

acute lymphoblastic leukemia; chemotherapy-induced peripheral neuropathy; pediatric cancer; quality of life; total neuropathy score

\section{Introduction}

Acute lymphoblastic leukemia (ALL) is the most common type of cancer in children (Gurney et al., 1995). Modern risk-based therapy for ALL has resulted in dramatically improved survival over the past 30 years (Pui and Evans, 2006), with 5-year survival rates now approaching $85 \%$ for children aged 14 years or younger at diagnosis (Gurney et al., 2006). Treatment of childhood ALL involves an average of 2-3 years of chemotherapy (Margolin et al., 2006), with multiple administrations of the neurotoxic drug vincristine. Chemotherapy-induced peripheral neuropathy (CIPN) is one of the most important dose-

\footnotetext{
(C) 2009 Peripheral Nerve Society

Address correspondence to: Sindhu Ramchandren, MD, MS, Department of Neurology, Detroit Medical Center, Wayne State University, 4201 St. Antoine, UHC 8C.20, Detroit, MI 48201, USA. Tel: +1 313-577-3515; Fax: +1 313-745-4216;

sramchan@med.wayne.edu.

The authors have no financial or other conflict of interest to report.
} 
limiting toxicities from exposure to vincristine (Ocean and Vhadat, 2004). CIPN manifests as painful dysesthesias, length-dependent sensory loss to pain, temperature and proprioception (legs worse than arms), suppression of deep tendon reflexes in proportion to sensory loss, difficulty with balance and coordination, and distal muscle weakness, consistent with nerve pathology (Windebank and Grisold, 2008). Patients with pre-existing neuropathies can develop life-threatening paralysis, even with low doses of vincristine (Hildebrandt et al., 2000). Electrophysiological studies show a distal axonal sensory-motor neuropathy (Sandler et al., 1969; Casey et al., 1973), but demyelination has also been seen (Hiser et al., 2008). Although the short-term development of signs and symptoms of CIPN is well-known among adults and children receiving vincristine (Holland et al., 1973; Vainionpää, 1993; Vainionpää et al., 1995), there is a paucity of data on the long-term consequences of vincristine exposure on the peripheral nervous system. The purpose of the present study was to determine the prevalence of neuropathy and its impact on motor function and quality of life (QOL) among a series of children who were at least 2 years off ALL therapy.

\section{Materials and Methods}

We identified 66 potential subjects aged 8 through 18 from the patient database of the LongTerm Follow-up Clinic in the Division of Pediatric Hematology-Oncology at the University of Michigan. Children with the following conditions that may result in neuropathy or muscle weakness independent of vincristine exposure were excluded from consideration as study subjects: diabetes, known history of neuropathy before ALL diagnosis, radiation treatment, and bone marrow transplantation. Children with trisomy 21 were also excluded. Eligibility criteria were met by 44 children; of these, four refused nerve conduction studies (NCS), two had incomplete vincristine dose information, and one participant's vincristine dosage was nearly 4 SD above the sample mean. Thus, after these exclusions, the final sample size was 37. Written informed consent was obtained from a parent for each subject and written assent was obtained from the participating child if he or she was aged 10 years or older. The project was approved by the University of Michigan Institutional Review Board.

The diagnosis of neuropathy is established by abnormalities in clinical history, examination, and nerve electrophysiology (England et al., 2005). All patients underwent a standardized complete neurological examination, portions of which were then translated to a severity score using the validated neuropathy impairment scale (NIS) (Dyck et al., 1980; 1985). Sural sensory and peroneal motor NCS were obtained in the leg, and median sensory and median motor NCS in the arm. Due to the paucity of literature on normative nerve conductions in young children, values that were two standard deviations below published means were established as abnormal (Hyllienmark et al., 1995). The reduced version of the total neuropathy score (TNSr), a validated composite measure of CIPN which includes symptoms, signs, and electrophysiological measures of the original TNS, but not the quantitative determination of vibration thresholds, was calculated for all patients. TNS and its reduced version correlate well with other measures (Miller et al., 1981; Oken et al., 1982; Ajani et al., 1990; Cavaletti et al., 2003; 2006). Most oncology and neurology experts now favor the use of the TNS scales over other measures in detecting and grading CIPN (Argyriou et al., 2008). A score of 1 or above on the TNS scales correlates with nerve pathology (Cornblath et al., 1999; Cavaletti et al., 2007).

Impact on motor function was assessed using the Bruininks-Oseretsky test of Motor Proficiency-Short Form (BOT), a validated measure of gross and fine motor skills for pediatric populations (Tabatabainia et al., 1995). Impact on QOL was assessed through the validated PedsQL 4.0 Generic Core Scales, which has been used successfully in childhood cancer populations (Varni et al., 2002). All study subjects also filled out a standardized 
medical history form. The Michigan autonomic symptoms survey, a standardized survey of autonomic symptoms in neuropathy, was also completed by each subject (Peltier et al., 2006). A standardized form was used to collect demographic- and treatment-related data from the patients' medical records.

\section{Statistical analysis}

Descriptive statistics for each neurological, functional, and psychosocial measure were summarized, and Student's $t$ tests and Fisher exact tests were used to examine group differences in continuous and categorical variables, respectively. The effects of time and sex, and separately of total vincristine dose and sex, were modeled on each of the outcome measures using linear regression. $\mathrm{R}^{2}$ statistics, reflecting the strength of the linear associations, were calculated.

\section{Results}

The demographic and treatment characteristics of the study subjects are summarized in Table 1. Subjects on average were aged 14.4 years and were 7.4 years post-treatment. The mean total vincristine dose for boys was significantly greater than that for girls (46.7 vs. $34.5 \mathrm{mg}, \mathrm{p}=0.01$ ), reflecting the longer maintenance treatment period and the larger body surface area in boys. Given this result, we included sex as a covariate in our regression models. All 37 children completed testing, including NCS required to calculate the TNSr, additionally, 35 of 37 children also agreed to median motor and sensory NCS.

\section{Clinical and electrodiagnostic studies}

No abnormalities were found on the Michigan autonomic symptoms survey. 11 of 37 children $(29.7 \%)$ reported subjective neuropathic symptoms. On examination, the mean NIS for these 11 children was 2.4, ranging from 0 to 12 , with 6 of the $11(54.5 \%)$ having NIS $\geq 1$. In comparison, the remaining 26 children had a mean NIS of 3.3, ranging from 0 to 17, with 19 of the $26(73.1 \%)$ having NIS $\geq 1$. Neither the mean difference nor difference in proportion were statistically significant ( $\mathrm{p}=0.48$ and 0.44 , respectively).

Peroneal motor, median sensory and/or median motor amplitudes that were two standard deviations below the published means were seen in 11 children (29.7\%). Eight of those children had peroneal compound muscle action potential (CMAP) amplitudes at or below $2.2 \mathrm{mV}$, three children had median CMAP amplitudes at or below $5 \mathrm{mV}$, and two children had median sensory amplitudes at or below $8 \mu \mathrm{V}$; this included two children with more than one impairment. Only 1 of the 11 children $(9.1 \%)$ with subjective symptoms had an abnormal nerve conduction study compared with 10 of the remaining 26 children (38.5\%) (p $=0.12$ ). The overall prevalence of NCS abnormalities was higher in boys than girls ( 33.3 vs. $23.1 \%$ ) and more boys than girls had reduced peroneal CMAP amplitudes (29.2 vs. $7.7 \%$ ), but neither difference reached statistical significance ( $\mathrm{p}=0.71$ and 0.22 , respectively).

As shown in Fig. 1, higher peroneal CMAP amplitudes were associated with longer time since treatment $\left(R^{2}=0.25 ; p=0.007\right)$. However, no appreciable linear association was observed in the study sample between the total vincristine dose and either the $\mathrm{TNSr}\left(\mathrm{R}^{2}=\right.$ $0.06 ; p=0.35)$ or peroneal CMAP amplitude $\left(R^{2}=0.12 ; p=0.10\right)$. Each of these linear regression models included sex as a covariate.

The prevalence of CIPN among the 37 children, as detected by a TNSr score of at least 1 , was $100 \%$. TNSr scores of 2 or higher were recorded in 35 (94.6\%) subjects in this clinical sample. Table 2 summarizes mean scores for the NIS, NCS, and TNSr. 


\section{Impact on motor function}

A negative linear association was observed between time since conclusion of treatment and BOT Z-score $\left(R^{2}=0.29\right.$ with sex as a covariate; $\left.p=0.003\right)$. However, only two subjects, both boys, tested in the abnormal range for motor function based on a BOT Z-score of -1 or lower (Table 3). The mean BOT Z-score among girls (0.57) was higher than that of boys $(-0.08 ; \mathrm{p}=0.02)$. No appreciable correlations were observed between BOT Z-scores and TNSr, peroneal CMAP amplitude, or total vincristine dose.

\section{Impact on QOL}

The study subjects' self-reported QOL results are also summarized in Table 3. The PedsQL total summary score was in the normal range of population values, with a mean score of 85.2. Mean scores on the PedsQL subscales ranged from 77.2 for school functioning to 89.6 for physical functioning. QOL scores for the boys tended to be higher than that of the girls, although the differences were not statistically significant. No substantive associations were observed between mean PedsQL scores and TNSr, peroneal CMAP amplitude, or total vincristine dose.

\section{Discussion}

Nearly all the childhood ALL survivors in this study had neuropathy, as evidenced by abnormal scores in the TNSr. A significant proportion also had abnormal NIS scores and NCS. The neuropathy appears to involve predominantly distal motor axons, as indicated by the larger percentage of children with reduced peroneal nerve amplitudes, compared with other nerve conduction abnormalities. Similarly low amplitudes were also seen in median sensory and median motor nerve responses, precluding the possibility of isolated foot trauma causing these abnormalities. Significantly, very few of our study subjects subjectively reported neurological complaints, even when there were documented nerve conduction abnormalities. The study subjects' motor neuropathy would have gone undetected with measures relying on subjective reporting of prominently sensory symptoms and foregoing nerve conduction testing. Treatment with vincristine at cumulative doses greater than $5 \mathrm{mg}$ leads to a dose-dependent neuropathy with sensory symptoms in most patients, and motor symptoms occur at cumulative doses of 30-50 mg (Casey et al., 1970). Although children with ALL receive high cumulative doses of vincristine (spread over an average of 39-month period for boys and 27-month period for girls), no relationship was seen between increasing dose and prevalence of neuropathy.

No appreciable effects of the neuropathy were noted on motor function or QOL. Recent studies, though, have shown an increased incidence of several components of the metabolic syndrome, perhaps increasing the likelihood of diabetes in long-term survivors of childhood ALL (Gurney et al., 2006). Given the study findings of a distal, axonal, predominantly motor neuropathy in these children, the additional impact of diabetes on their long-term neuromuscular function and QOL could be significant.

This study also had some limitations. The autonomic nervous system was not quantitatively assessed, but no evidence of autonomic nerve dysfunction was found on the Michigan autonomic symptoms survey. Children with ALL receive other medications besides vincristine during the acute phase of illness: steroids, L-asparaginase, methotrexate, 2 amino-6-mercaptopurine, 6-thioguanine, cyclophosphamide, anthracyclines (adriamycin and daunorubicin), and cytarabine; treatments are tailored according to the ALL risk stratification of the child. Of those drugs, vincristine is the only one with known peripheral neurotoxicity; it is unknown whether the combination of the other drugs may be toxic to nerves as well. The phenomenon of coasting, where peripheral nerve dysfunction becomes 
evident weeks to months after discontinuation of treatment, has been reported with pyridoxine (Berger et al., 1992) and more recently with the platinum compounds (Windebank and Grisold, 2008). Our study population showed symptoms several years after discontinuation of vincristine, without any subjective symptoms of neuropathy in between. If the children had neuropathies stemming from weight fluctuations and frequent ICU admissions, this should have been known to the families; one of our study exclusion criteria was known neuropathy at the present time.

A few other studies support the findings we observed in these childhood ALL survivors. One study that evaluated children 6 months after their last vincristine dose found sensory abnormalities in 33\% of tested patients (Reinders-Messelink et al., 2000). A small study of 18 childhood ALL survivors showed handwriting problems in $25 \%$ of the children 2 years after treatment completion, which was hypothesized to be related to vincristine-related peripheral neuropathy (Reinders-Messelink et al., 1996); however, a more recent blinded study did not confirm those findings (Hartman et al., 2007). A motor functional assessment study comparing survivors of childhood ALL who were off therapy for a mean of 4.7 years (range 1-13.6) with a healthy population found statistically significant lower scores in the balance subtests; one of the possible factors for this deficit was hypothesized to be neuropathy, although a neurological assessment was not conducted (Wright et al., 2005).

\section{Conclusion}

CIPN is an important dose-limiting toxicity of vincristine in the treatment of childhood ALL. It is widely believed that the neurotoxicity seen with vincristine is an acute event. Our study shows nerve conduction abnormalities in children who are more than 2 years off therapy for childhood ALL. The distal, axonal motor neuropathy does not seem to significantly impact their motor function or QOL at present. Further research is required to assess and limit the long-term impact of this distal axonal motor neuropathy on motor functional status and QOL.

\section{Acknowledgments}

This study was supported by the National Research Service Award for Training in Clinical Research (T32 NS07222-23; Dr. Ramchandren), the National Institute of Health's Clinical Research Curriculum Award (K30 HL04108; Dr. Ramchandren), and the Nancy Newton Loeb Pediatric Oncology Award at the University of Michigan (Dr. Gurney and Dr. Ramchandren).

\section{References}

Ajani JA, Welch SR, Raber MN, Fields WS, Krakoff IH. Comprehensive criteria for assessing therapy-induced toxicity. Cancer Invest. 1990; 8:147-159. [PubMed: 2400936]

Argyriou AA, Iconomou G, Kalofonos HP. Bortezomib-induced peripheral neuropathy in multiple myeloma: a comprehensive review of the literature. Blood. 2008; 112:1593-1599. [PubMed: 18574024]

Berger AR, Arezzo JC, Schaumburg HH, Schroeder C, Apfel S, Reynolds R. Dose response, coasting and differential fiber vulnerability in human toxic neuropathy: a prospective study of pyridoxine neurotoxicity. Neurology. 1992; 42:1367-1370. [PubMed: 1620347]

Casey EB, Fullerton PM, Jelliffe AW. Vincristine neurotoxicity: a clinical and electrophysiological study of eighteen patients. Clin Sci. 1970; 38:23P-24P.

Casey EB, Jellife AM, Le Quesne PM, Millett YL. Vincristine neuropathy. Clinical and electrophysiological observations. Brain. 1973; 96:69-86. [PubMed: 4348690]

Cavaletti G, Bogliun G, Marzorati L, Zincone A, Piatti M, Colombo N, Parma G, Lissoni A, Fei F, Cundari S, Zanna C. Grading of chemotherapy-induced peripheral neurotoxicity using the total neuropathy scale. Neurology. 2003; 61:1297-1300. [PubMed: 14610145] 
Cavaletti G, Jann S, Pace A, Plasmati R, Siciliano G, Briani C, Cocito D, Padua L, Ghiglione E, Manicone M, Giussani G. Italian NETox Group. Multi-center assessment of the total neuropathy score for chemotherapy-induced peripheral neurotoxicity. J Peripher Nerv Syst. 2006; 11:135-141. [PubMed: 16787511]

Cavaletti G, Frigeni B, Lanzani F, Piatti M, Rota S, Briani C, Zara G, Plasmati R, Pastorelli F, Caraceni A, Pace A, Manicone M, Lissoni A, Colombo N, Bianchi G, Zanna C. Italian NETox Group. The total neuropathy score as an assessment tool for grading the course of chemotherapyinduced peripheral neurotoxicity: comparison with the national cancer institute-common toxicity scale. J Peripher Nerv Syst. 2007; 12:210-215. [PubMed: 17868248]

Cornblath DR, Chaudhry V, Carter K, Lee D, Seysedadr M, Miernicki M, Joh T. Total neuropathy score: validation and reliability study. Neurology. 1999; 53:1660-1664. [PubMed: 10563609]

Dyck PJ, Sherman WR, Hallcher LM, Service FJ, O'Brien PC, Grina LA, Palumbo PJ, Swanson CJ. Human diabetic endoneurial sorbitol, fructose, and myo-inositol related to sural nerve morphometry. Ann Neurol. 1980; 8:590-596. [PubMed: 7212646]

Dyck PJ, Karnes JL, Daube J, O'Brien P, Service FJ. Clinical and neuropathological criteria for the diagnosis and staging of diabetic polyneuropathy. Brain. 1985; 108:861-880. [PubMed: 4075076]

England JD, Gronseth GS, Franklin G, Miller RG, Asbury AK, Carter GT, Cohen JA, Fisher MA, Howard JF, Kinsella LJ, Latov N, Lewis RA, Low PA, Sumner AJ. Distal symmetrical polyneuropathy: definition for clinical research. Muscle Nerve. 2005; 31:113-123. [PubMed: 15536624]

Gurney JG, Severson RK, Davis S, Robison LL. Incidence of cancer in children in the United States: sex-, race-, and 1-year age-specific rates by histologic type. Cancer. 1995; 75:2186-2195. [PubMed: 7697611]

Gurney, J.; Bondy, M. Epidemiology of childhood cancer. In: Pizzo, PA.; Poplack, DG., editors. Principles and Practice of Pediatric Oncology. Philadelphia: Lippincott Williams \& Wilkins; 2006. p. 1-13.

Gurney JG, Ness KK, Sibley SD, O'Leary M, Dengel DR, Lee JM, Youngren NM, Glasser SP, Baker KS. Metabolic syndrome and growth hormone deficiency in adult survivors of childhood acute lymphoblastic leukemia. Cancer. 2006; 107:1303-1312. [PubMed: 16894525]

Hartman A, van den Bos C, van Dartel N, Stijnen T, Pieters R. No adverse effect of vincristine on handwriting in children after completion of therapy. Pediatr Blood Cancer. 2007; 49:841-845. [PubMed: 16960868]

Hildebrandt G, Holler E, Woenkhaus M, Quarch G, Reichle A, Schalke B, Andreesen R. Acute deterioration of Charcot-Marie-Tooth disease 1A (CMT 1A) following $2 \mathrm{mg}$ of vincristine chemotherapy. Ann Oncol. 2000; 11:743-747. [PubMed: 10942065]

Hiser L, Harrington B, Lobert S. Effect of noscapine and vincristine combination on demyelination and cell proliferation in vitro. Leuk Lymphoma. 2008; 49:1603-1609. [PubMed: 18766974]

Holland JF, Scharlau C, Gailani S, Krant MJ, Olson KB, Horton J, Shnider BI, Lynch JJ, Owens A, Carbone PP, Colsky J, Grob D, Miller SP, Hall TC. Vincristine treatment of advanced cancer: a cooperative study of 392 cases. Cancer Res. 1973; 33:1258-1264. [PubMed: 4352365]

Hyllienmark L, Ludvigsson J, Brismar T. Normal values of nerve conduction in children and adolescents. Electroencephalogr Clin Neurophysiol. 1995; 97:208-214. [PubMed: 7489681]

Margolin, JF.; Steuber, CP.; Poplack, DG. Acute lymphoblastic leukemia. In: Pizzo, PA.; Poplack, DG., editors. Principles and Practice of Pediatric Oncology. Philadelphia: Lippincott Williams \& Wilkins; 2006. p. 538-590.

Miller AB, Hoogstraten B, Staquet M, Winkler A. Reporting results of cancer treatment. Cancer. 1981; 47:207-214. [PubMed: 7459811]

Ocean AJ, Vhadat LT. Chemotherapy-induced peripheral neuropathy: pathogenesis and emerging therapies. Support Care Cancer. 2004; 12:619-625. [PubMed: 15258838]

Oken MM, Creech RH, Tormey DC, Horton J, Davis TE, McFadden ET, Carbone PP. Toxicity and response criteria of the Eastern Cooperative Oncology Group. Am J Clin Oncol. 1982; 5:649-655. [PubMed: 7165009] 
Peltier AC, Consens FB, Sheikh K, Wang L, Song Y, Russell JW. Autonomic dysfunction in obstructive sleep apnea is associated with impaired glucose regulation. Sleep Med. 2006; 8:149_ 155. [PubMed: 17236808]

Pui CH, Evans WE. Treatment of acute lymphoblastic leukemia. N Engl J Med. 2006; 354:166-178. [PubMed: 16407512]

Reinders-Messelink HA, Schoemaker MM, Hofte M, Goeken LN, Kingma A, van den Briel MM, Kamps WA. Fine motor and handwriting problems after treatment for childhood acute lymphoblastic leukemia. Med Pediatr Oncol. 1996; 27:551-555. [PubMed: 8888816]

Reinders-Messelink HA, Van Weerden TW, Fock JM, Gidding CE, Vingerhoets HM, Schoemaker MM, Goeken LN, Bokkerink JP, Kamps WA. Mild axonal neuropathy of children during treatment for acute lymphoblastic leukaemia. Eur J Paediatr Neurol. 2000; 4:225-233. [PubMed: 11030069]

Sandler SG, Tobin W, Henderson ES. Vincristine-induced neuropathy. A clinical study of fifty leukemic patients. Neurology. 1969; 19:367-374. [PubMed: 5813374]

Tabatabainia MM, Ziviani J, Maas F. Construct validity of the Bruininks-Oseretsky test of motor proficiency and the Peabody developmental motor scales. Aust Occup Ther J. 1995; 42:3-13.

Vainionpää L. Clinical neurological findings of children with acute lymphoblastic leukaemia at diagnosis and during treatment. Eur J Pediatr. 1993; 152:115-119. [PubMed: 8444217]

Vainionpää L, Kovala T, Tolonen U, Lanning M. Vincristine therapy for children with acute lymphoblastic leukemia impairs conduction in the entire peripheral nerve. Pediatr Neurol. 1995; 13:314-318. [PubMed: 8771166]

Varni JW, Burwinkle TM, Katz ER, Meeske K, Dickinson P. The PedsQL in pediatric cancer: reliability and validity of the pediatric quality of life inventory generic core scales, multidimensional fatigue scale, and cancer module. Cancer. 2002; 94:2090-2106. [PubMed: 11932914]

Windebank AJ, Grisold W. Chemotherapy-induced neuropathy. J Peripher Nerv Syst. 2008; 13:27-46. [PubMed: 18346229]

Wright MJ, Galea V, Barr RD. Proficiency of balance in children and youth who have had acute lymphoblastic leukemia. Phys Ther. 2005; 85:782-790. [PubMed: 16048425] 


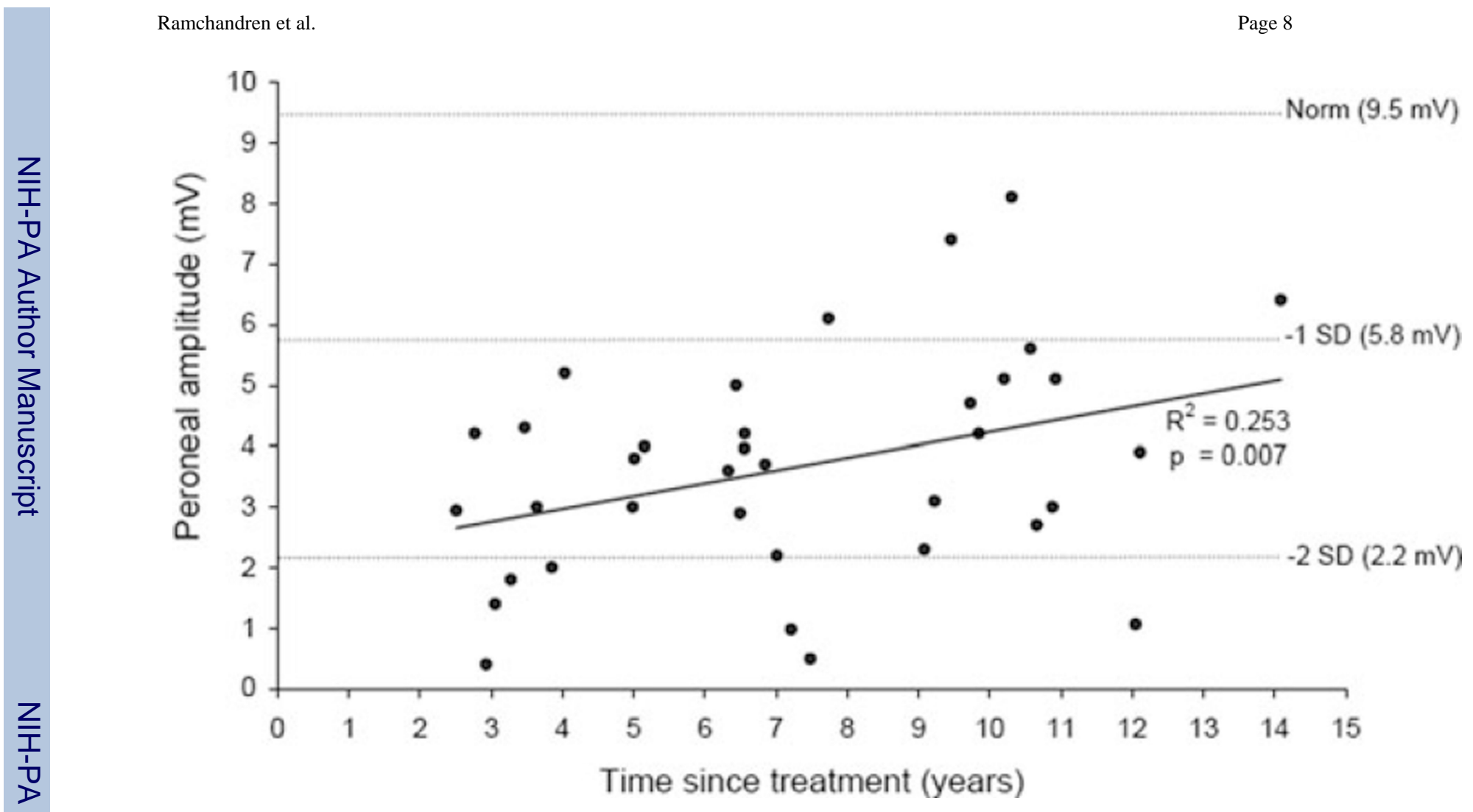

Figure 1.

Association between peroneal motor amplitude and time since treatment. 
Table 1

Demographic and treatment information.

\begin{tabular}{lc}
\hline & Mean (SD) \\
\hline Age at diagnosis in years & $3.9(2.3)$ \\
Age at interview in years & $14.4(2.8)$ \\
Years since treatment & $7.4(3.2)$ \\
Total vincristine in mg & $42.4(14.2)$ \\
Males & $46.7(12.0)$ \\
Females & $34.5(14.8)$ \\
\hline
\end{tabular}




\section{Table 2}

Assessment of neuropathy: results from the neurological examinations, nerve conduction studies, and composite total neuropathy score.

\begin{tabular}{lcc}
\hline Mean scores (SD) & Subjects $(\mathbf{n}=\mathbf{3 7})$ & Population norms \\
\hline Neuropathy impairment score (NIS) & $3.0(3.6)$ & 0 \\
Nerve conduction studies (NCS) & & \\
Peroneal nerve CMAP amplitude $(\mathrm{mV})$ & $3.8(2.0)$ & $9.5(3.7)$ \\
Sural nerve SNAP amplitude $(\mu \mathrm{V})$ & $16.1(9.9)$ & $14.4(7.0)$ \\
Median nerve CMAP amplitude $(\mathrm{mV})$ & $10.1(3.6)$ & $25.7(8.9)$ \\
Median nerve SNAP amplitude $(\mu \mathrm{V})^{\dagger}$ & $36.8(18.4)$ & \\
Total neuropathy score reduced (TNSr) & $4.0(2.0)$ & \\
\hline CMAP, compound muscle action potential; SNAP, sensory nerve action potential. \\
$*$ \\
One child refused median nerve CMAP.
\end{tabular}




\section{Table 3}

Motor functional assessment and quality of life scores.

\begin{tabular}{lcccc}
\hline & Overall $(\mathbf{n}=\mathbf{3 7})$ & Female $(\mathbf{n}=\mathbf{1 3})$ & Male $(\mathbf{n}=\mathbf{2 4})$ & $\mathbf{p}$ \\
\hline BOT & & & & \\
Z-score, mean (SD) & $0.15(0.82)$ & $0.57(0.75)$ & $-0.08(0.77)$ & 0.02 \\
Category, n (\%) & & & & 0.03 \\
Well-below average (Z-score $\leq-2.0)$ & 0 & 0 & 0 & \\
Below average (Z-score -1.0 to -1.9) & $2(5.4 \%)$ & 0 & $2(8.3 \%)$ & \\
Average (Z-score -0.9 to 0.9) & $28(75.7 \%)$ & $8(61.5 \%)$ & $20(83.3 \%)$ & \\
Above average (Z-score 1.0 to 1.9) & $6(16.2 \%)$ & $5(38.5 \%)$ & $1(4.2 \%)$ & \\
Well-above average (Z-score 22.0$)$ & $1(2.7 \%)$ & 0 & $1(4.2 \%)$ & \\
Quality of life [mean (SD)] & & & & \\
Total & $85.2(11.6)$ & $81.8(13.7)$ & $87.0(10.2)$ & 0.20 \\
Physical & $89.6(11.4)$ & $87.1(13.6)$ & $91.0(10.1)$ & 0.33 \\
Psychosocial summary & $82.7(13.1)$ & $79.0(14.6)$ & $84.8(12.1)$ & 0.20 \\
Emotional & $81.4(15.9)$ & $75.8(17.7)$ & $84.4(14.3)$ & 0.12 \\
Social & $89.6(12.5)$ & $87.3(15.1)$ & $90.8(11.1)$ & 0.42 \\
School & $77.2(17.7)$ & $73.8(18.5)$ & $79.0(17.4)$ & 0.41 \\
\hline
\end{tabular}

